\title{
A INVERSÃO DO ÔNUS DA PROVA COMO INSTRUMENTO DE EFETIVIDADE NA PRESTAÇÃO DA TUTELA JURISDICIONAL DOS INTERESSES DOS CONSUMIDORES
}

\author{
Cláudio Castello de Campos Pereira \\ Graduado pela Faculdade de Direito da Universidade de \\ São Paulo. Advogado em São Paulo.
}

Resumo:

A evolução da processualística e seu atual contexto; as razões de ser do Direito consumerista; a inclusão do ônus da prova no Código de Defesa do Consumidor, perfazem a abordagem do autor em torno da inversão do ônus da prova como instrumento de efetividade na prestação da tutela jurisdicional dos interesses dos consumidores.

Abstract:

The processualistic evolution and its actual context; the reasons of the consumer's Law; the inclusion of the proof onus in the Consumer's Defense Code, accomplish the author's boarding around the proof onus inversion as an instrument of effectiveness in the given of jurisdictional tutelage of the consumers's interests.

Unitermos: evolução processualística; inversão do ônus da prova; Código de Defesa do Consumidor.

1. Evolução da Processualística e seu Contexto Atual.

O problema do ônus da prova é a regra segundo a qual ao queixoso incumbe o ônus da demonstração dos fatos que alegar para a persecução de seu direito em juizo. É, pois, princípio regido pelo adágio romano "actori incumbit probatio". Segundo Gilissen, é um princípio processual antigo,' contemporâneo da introdução e imposição, na evolução natural do direito romano, do sistema "racional" de produção das provas, o que se deu nos séculos XII e XIII. ${ }^{2}$ Num

I. Cf. John Gilissen, Introdução Histórica ao Direito, trad. por Antonio Manucl Hespanha c Manucl Macaista Malhciros, 1996, Lisboa, Fundação Caloustc Gulbckian, itcm 2, pp. 713-714.

2. Vale a lembrança das considerações do ilustre professor de História Medicval c de História do Dircito da Universidade de Ghent, R. C. van Cacnegem, para quẹm a cvolução do sistema racional do dircito de prova foi tambćm influcnciado pclo proccsso romano-canônico, mas sua importância não há de scr cxagcrada, pois o renascimento do Dircito Romano não foi uma causa próxima dessa transformação (Uma introdução histórica ao Direito Privado, trad. por Carlos Eduardo Machado, 1995, São Paulo, Martins Fontcs, p. 107) 
primeiro momento, diz, o ônus da prova era do Tribunal, posteriormente repassado ao autor da queixa. A partir do século XIII, impõe-se progressivamente; tornandose, em época moderna, uma regra geral, tanto em matérias cíveis quanto criminais. O Direito Processual fará parte desse contexto desde o seu nascimento como ramo autônomo da Ciência do Direito. Nas palavras de Francesco Carnelutti, "a produção de um fato torna-se um ônus para a parte que tem interesse na sua afirmação. Desse principio, dá-nos uma formulação aproximada da fórmula animus probandi et incumbit qui dicit; non qui negat, mas, para ser exata, nela há que retificar o quit dicit por cui dicere prodest e reciprocamente o qui negat por cui dicere nocet $o u$ cui negare prodest" 3 Essa concepção trouxe seus reflexos para o ordenamento jurídico brasileiro, e a regra do ônus probatório está estampada no art. 333, incs. I e II, do Código de Processo Civil, que impõe ao autor a prova do fato constitutivo de seu direito e ao réu, quanto à existência de fato impeditivo, modificativo ou extintivo do direito do autor.

Entretanto, a expansão da economia mundial verificada na última metade do século XX provocou transformações significativas em diferentes aspectos da vida social, dentre as quais e de maneira destacada o crescimento do mercado de consumo, surgindo a necessidade da presença estatal para a regulação de atividades até então consideradas privadas. No Brasil, o reflexo direto de tal afirmação está na edição de uma lei específica para a disciplina do mercado de consumo, surgindo, neste contexto, o Código de Defesa do Consumidor (Lei n. 8.078/90). Em seu bojo há mudanças significativas no campo do Direito Processual: além da disciplina mais aprofundada das ações coletivas, trouxe-se a exceção à regra "actori incumbit probatio", prescrevendo como direito básico do consumidor "a facilitação da defesa de seus direitos, inclusive com a inversão do ônus da prova, a seu favor, no processo civil, quando, a critério do juiz, for verossimil a alegação ou quando for ele hipossuficiente, segundo as regras ordinárias de experiências" (art. $6^{\circ}$ VIII grifamos).

O espirito dessa norma está diretamente relacionado com o acesso dos cidadãos (no caso, dos consumidores) à Justiça, ou, na expressão cunhada na doutrina brasileira, "acesso à ordem jurídica justa". Aqui entramọs, então, numa das candentes questões da processualística atual, que é a efetividade do processo ${ }^{4}$, significando enfrentar tema correspondente à mais moderna e premente das preocupações dos processualistas de nosso tempo.

Não é possível, pois, falar de efetividade do processo sem que possamos observá-la dentro do prisma da evolução da Ciência do Direito

3. Teoria Gcral do Dircito, 2000, São Paulo, Lejus, pp.541-542

4. Terminologia usada por José Carlos Barbosa Morcira para transmitir a noçào de que o processo deve ser utilizado como instrumento efetivo $\mathrm{c}$ apto para resolução de litigios, $\mathrm{cm}$ Notas sobre o problema da "efetividade" do processo, in Temas de Direito Processual: Terceira Série, 1984, São Paulo, Editora Saraiva, p. 27. 
Processual (ramo "recente" do direito, tendo em vista que seu surgimento deu-se há cerca de menos de um século e meio).

A Ciência do Processo tem como nascedouro, segundo alguns autores, a obra de Oscar von Bülow, que escreveu, em 1868, um estudo sobre a teoria das exceções dilatórias e os pressupostos processuais, enfatizando a origem etimológica da palavra "processo" e mostrando, pela primeira vez, que o processo é um fenômeno jurídico próprio, que depende de requisitos próprios, regidos por regras e princípios que lhe são específicos, merecendo, com isso, um tratamento jurídico autônomo, dadas as peculiaridades do objeto observado. Este estudo diferenciava, com maior nitidez, a relação material litigiosa da relação jurídica processual, apresentando o processo mais como meio de pacificação social que via de composição de litígios, de modo a coroar a função pacificadora/jurisdicional do Estado, daí porque era ramo do Direito Público. 5

A partir de então, a preocupação dos cientistas desse novo ramo do Direito - primeiramente na Alemanha e depois em outras escolas tornou-se a investigação da chamada autonomia da ação, baseando-se na velha idéia romana de que a actio era um direito contra o pretor (uma idéia reducionista, é verdade, pois era muito mais que isso), e esforçando-se, por outro lado, em demonstrar que a ação não se confundia com o direito material, rompendo com a antiqüíssima tradição romana de quase dois milênios, na qual a ação (actio) era o direito (ius), e vice-versa, uma vez que o sistema romano era um sistema de ações, e não de direitos. $^{6}$

Os cientistas, a partir de Bülow, preocuparam-se primordialmente com construção das estruturas científicas do Direito Processual, daí porque formaram a chamada escola autonomista, ou conceitual, fase que durou, para essa ciência, cerca de um século. Já no final do século XIX, da escola dos autonomistas puros derivam as teorias concretistas, segundo as quais a ação era um direito como um direito concreto (direito a uma sentença favorável), uma vez que ação não se confunde com o Direito Processual, embora dele dependa" . No Brasil, Ada Pellegrini Grinover credita, nesse período, às figuras de Paulo Batista, no Processo Civil, e Pimenta Bueno, no Processo Penal, o surgimento das primeiras

5. Cf. Eduardo Arruda Alvim, Curso de Direito Processual Civil, 1999, São Paulo, Editora Revista dos Tribunais, p.28.

6. Sobre cssa conccpção, vale transcrever cxcerto da importante lição de Antônio Carlos de Araújo Cintra, Ada Pellegrini Grinover c Cândido Rangel Dinamarco: "Até meados do século passado, o processso era considerado simples meio de exercicio de direitos (...) A ação era entendida como sendo o próprio direito subjetivo material yue, una vez lesado, adquiria forças para obter em juizo a reparação da lesão sofrida", Teoria Geral do Processo, 1998, São Paulo, Malhciros Editores, p.42.

7. Uma tcoria importante, mas que não respondia a outras questões tcóricas igualmente importantes, como as conseqüências da declaração de improcedência da ação, as quais enscjariam questionamento sobrc a própria existência da ação $\mathrm{cm}$ face da declaração de improccdência. Assim, pergunta-sc, por cxemplo, donde nasccria o processo, ou scja a provocação originária da tutcla jurisdicional? 
noções sobre Direito Processual, pelo esforço de descortinar "horizontes desconhecidos pela própria processualistica européia da Época"s

A essas teorias sobrevieram outras, preocupadas com a questão da autonomia do Direito Processual, ainda no começo do século XX: teorias sobre a natureza abstrata da ação, segundo as quais a teoria da ação estava totalmente dissociada da relação material litigiosa, estando mais afeta ao direito de obtenção de uma sentença de mérito. Essa teoria teve grande importância, embora apresentasse suas deficiências.

Não poderíamos deixar de registrar a teoria eclética do Enrico Tullio Liebman, jurista italiano erradicado posteriormente no Brasil, na Faculdade de Direito do Largo de São Francisco, que veio a dominar a Doutrina mundial e especialmente a brasileira, ${ }^{9}$ tendo suas concepções refletidas com profundidade no legislador brasileiro, uma vez que o Código Civil brasileiro adotou integralmente suas teorias, pelas quais a ação tem seus elementos primordialmente abstratos, indubitavelmente, embora dependa também de elementos concretos, como as condições da ação, que se vinculam a situações concretas afirmadas em juízo, a partir das quais o juiz poderá decidir se existe direito a uma sentença de mérito.

Essas foram as importantes etapas da Ciência Processual: a autonomia da ação, a ação como um direito abstrato e, em seguida, a ação como o direito a uma sentença de mérito. Mas essas teorias careciam, ainda, de algumas deficiências teóricas, muitas das quais deram-se pela visão puramente introspectiva da abordagem, extremamente tecnicista, vendo o processo como uma preocupação em si, despindo-lhe de seu aspecto crítico e deixando, conseqüentemente, de se observar o impacto real de seus resultados, distanciando-se de sua verdadeira função, que é, como vimos, a via de Estado exercer, de forma efetiva, a sua função pacificadoraljurisdicional da litigiosidade social.

$\mathrm{Na}$ segunda metade do século XX, então, o processo se desenvolve com uma outra necessidade: a de se colocar no centro da análise processualística a jurisdição, passando a Ciência Processual a desempenhar maior consciência e crítica. Pois analisar o processo a partir da ação é observá-lo numa perspectiva eminentemente individualista, ainda sob os refletores do liberalismo; analisar o processo sob a ótica do próprio processo é observá-lo numa perspectiva tecnicista; mas analisar o processo na perspectiva da prestação do serviço jurisdicional é coadunar-se com a sua função última e primordial, qual seja servir de instrumento do qual dispõe o poder estatal para exercer a verdadeira pacificação dos litígios comuns ao convívio social.

8. Cf. O Processo em Evolução, 1998, São Paulo, 2a cdição, Editora Forcnsc Univcrsitária, p. 2

9. Ada Pellegrini Grinover credita a Licbman o surgimento da escola processual de São Paulo, que de tamanho vulto tornou-se a escola brasileira, internacionalmente reconhecida. Licbman acabou por congregar em torno de si jovens estudiosos do processo civil, como José Frederico Marques c Alfredo Buzaid, cstc ativo militante quando da claboração do atual Código de Processo Civil, cm 1973, alćm da própria autora c de Cândido Rangel Dinamarco (ob. cit., p. 5.) 
Essa é a atual fase instrumentalista do processo, eminentemente crítica, ${ }^{10}$ fase que sucede aquela primeira, a escola dos autonomistas. ${ }^{11}$

Essa atual fase do processo evolutivo da Ciência Processual surge como decorrência da reafirmação dos Estados Nacionais Soberanos após o período das Grandes Guerras que abalaram e alteraram profundamente o mundo, ao mesmo tempo em que se observava o crepúsculo do proselitismo cego das concepções liberais que tanto nortearam o ambientes político, econômico e jurídico dos séculos XIX e início do século XX, consolidando-se os princípios de intervenção estatal na vida privada.

Nesse contexto está a formulação das disciplinas constitucionais do processo (ou as concepções processuais na Constituição), relacionando o processo no rol das garantias do cidadão - como o devido processo legal e a ampla defesa tendo como expressão máxima as contribuições de José Frederico Marques e, posteriormente, Ada Pellegrini Grinover. A bem da verdade, o Direito Processual Constitucional já é esboçado no final do século XIX, aparecendo na Constituição Republicana de $1891 \mathrm{com}$ institutos como o controle judicial dos atos administrativos e alguns instrumentos de garantia das garantias individuais, ${ }^{12}$ como o Habeas Corpus, cuja Doutrina brasileira é uma das mais sofisticadas do mundo, até os dias de hoje.

Durante as décadas de 60 e principalmente de 70 , os cientistas de todo o mundo procuraram enfocar tais questões no acesso à Justiça, gerando proficuas discussões sobre o acesso de qualquer cidadão ao serviço de prestação estatal do serviço judiciário. Este periodo, que teria se iniciado em 1965, marca o que Mauro Cappelletti e Bryant Garth chamaram de "primeira onda" 13 Este é um ponto fundamental na abordagem deste estudo.

Sobre esse atualíssimo tema, os juristas bem lá diziam, em 1978:

"O enfoque sobre o acesso - o modo pelo qual os direitos se tornam efetivos - também caracteriza crescentemente o estudo do moderno processo civil. A discussão teórica, por exemplo, das várias regras do processo civil e de como elas podem ser manipuladas em várias situações hipotéticas pode ser instrutiva, mas, sob essas descrições neutras, costuma ocultar-se o modelo freqüentemente irreal de duas (ou mais) partes em igualdade de condições perante a corte, limitadas

10: Cf. Antônio Carlos de Araújo Cintra, Ada Pellegrini Grinover c Cândido Rangcl Dinamarco, ob. cit., p.43.

11. Cf. Antônio Carlos de Araújo Cintra, Ada Pcllegrini Grinover c Cândido Rangcl Dinamarco, ob. cit., pp.42-45.

12. Cf. Ada Pellegrini Grinover, ob. cit., pp. 6-7

13. Acesso à Justiça, trad. por Ellen Gracic Northflect, 1988, Porto Alcgre, Sćrgio Antonio Fabris Editor, pp. 31-49 
apenas pelos argumentos juridicos que os experientes advogados possam alinhar. O processo, no entanto, não deveria ser colocado no vácuo. Os juristas precisam, agora, reconhecer que as técnicas processuais servem a funções sociais; que as cortes não são a única forma de solução de conflitos a ser considerada e que qualquer regulamentação processual, inclusive a criação ou encorajamento de alternativas ao sistema judiciário formal tem um efeito importante sobre a forma como opera a lei substantiva - com que freqüência ela é executada, em beneficio de quem e com que impacto social. Uma tarefa básica dos processualistas modernos é expor o impacto substantivo dos vários mecanismos de processamento de litigios. Eles precisam, conseqüentemente, ampliar sua pesquisa para mais além dos tribunais e utilizar os métodos de análise da sociologia, da política, da psicologia e e da economia, e ademais, aprender através de outras culturas. $O$ "acesso" não é apenas um direito social fundamental, crescentemente reconhecido; ele é, também, necessariamente, o ponto central da moderna processualistica. Seu estudo pressupõe um alargamento e aprofundamento dos objetivos e métodos da moderna ciência jurídica. "14

Nesse espírito e com tal preocupação, Kazuo Watanabe cunhou a feliz expressão "acesso à ordem jurídica justa" is que foi vista com bons olhos pela doutrina

Este é, indubitavelmente, o princípio que motivou o legislador brasileiro à edição da Lei n. 9.099/95, que institui os tribunais especiais para o julgamento de pequenas causas, e, em âmbito administrativo, correlacionado à função estatal para a prevenção e resolução de conflitos em matéria consumerista, a criação de órgãos administrativos que compõe o Sistema Nacional de Proteção ao Consumidor, como o caso do PROCON, no Estado de São Paulo.

Embora de maneira tímida, há a lenta e ainda precária implementação, nas agências reguladoras e fiscalizadoras dos serviços públicos delegados (como ANATEL, ANEEL etc.), também em esfera administrativa, de serviços de atendimento às queixas dos consumidores, embora esse mecanismo se preste a tratar dos interesses da coletividade de consumidores, e não dos interesses dos consumidores individualmente considerados.

Importante, também, registrar a experiência Argentina no tocante ao mecanismo de tribunais arbitrais, prevista no art. 59 da Lei n. 24.240, regulamentada a implementação desses dispositivos pelo Decreto n. 276/98 e a

14. ob. cit., pp. 12-13.

15. Acesso à justiça na Sociedade Moderna, in Participação e Processso, 1988, Sào Paulo, Editora Revista do Tribunais, pp. 128-135. 
Resolução n. 212/98, da Secretaría de Industria, Comercio y Minería. Tal mecanismo compõe o "Sistema Nacional de Arbitraje de Consumo- SNAC" e tem-se mostrado, naquele país, um sofisticado meio de resolução rápida e eficiente de conflitos, estando esse sistema baseado nos princípios da voluntariedade, no caráter vinculante e executável das decisões, na simplicidade e na rapidez, na neutralidade e no equilibrio das partes, na competência dos tribunais arbitrais, na flexibilidade procedimental, e na promoção pública de adesão a esse sistema ${ }^{16}$

Prosseguindo na apresentação da evolução da Processualística brasileira, teremos já nos anos 80 o surgimento de novas preocupações e percepções, focadas principalmente na representação e na tutela dos interesses e nos direitos metaindividuais (ou supraindividuais), nos interesses difusos, nos interesses coletivos ou grupais, bem como no reconhecimento legal da categoria dos interesses individuais homogêneos, gerando reflexos e impactos diretos no ordenamento brasileiro, como a Lei n. 7.347/85, que disciplina a Ação Civil Pública, ou ainda a Constituição de 1988, que de pioneiramente tratou em sede da Lei Maior a disciplina dos interesses difusos e coletivos, entre outras diversas medidas. É a introdução, no seio da processualística, dos sofisticados mecanismos das "class actions" e das ações de interesse público. A tal fase Cappelletti e Garth chamaram de "segunda onda". ${ }^{17}$ Segundo os autores, tais modificações teriam forçado profundas reflexões sobre "noções tradicionais muito básicas do processo civil e sobre o papel dos tribunais". ${ }^{18}$

Nesse processo pode ser constatada a crescente importância da figura do Ministério Público, no Brasil, para a tutela de tais interesses, o que a Constituição de 1988 bem refletiu essas tendências, disciplinando e ampliando os poderes dessa Instituição para a persecução de tais interesses.

A "terceira onda" a que já faziam apologia os autores, acabou por se concretizar nas questões afetas ao que se chama, hoje, de efetividade do processo. Em outras palavras, a preocupação se dá em torno dos resultado práticos do processo. Tal fase está "longe de exaurir o seu potencial reformista. Durante ela já foi possivel tomar consciência do relevantíssimo papel deontológico do sistema processual e de sua complexa missão perante a sociedade e o Estado, e não só em face da ordem juridico material..." 19

Como dissemos, o tema "efetividade do processo" é ainda candente nas discussões atuais da processualística. Para Cândido Rangel Dinamarco,

16. Cf. Ricardo Lcandro Nasio. El Consumidor-Conflitos \& Soluciones, 1999, Bucnos Aircs, Edicioncs del Pais, pp. 287-292.

17. ob. cit., pp: $49-67$

18. ob. cit., p. 49.

19. Cf. Antônio Carlos de Araújo Cintra, Ada Pellegrini Grinover c Cândido Rangel Dinamarco, $o b$. cit., pp.43-44. 
"significa a sua almejada aptidão a eliminar insatisfações, com justiça e fazendo cumprir o direito, além de valer como meio de educação geral para o exercício e respeito dos direitos e canal de participação dos individuos nos destinos da sociedade e assegurar-lhes a liberdade" ${ }^{20}$ Veja-se que, em síntese, o autor ressalta o escopo da função pacificadora do processo, que seria uma via para que essa função "socio-político-jurídica" seja alcançada. Tal objetivo é igualmente bem explicitado em outra monumental obra: "Sentenças, decisões comandos e remédios ditos heróicos concedidos por juizes e tribunais não passariam de puras balelas, não fora pelo resultado prático que sejam capazes de produzir na vida das pessoas e nas efetivas relações com outras e com os bens da vida. O pensador moderno não encara mais o processo, como dantes, a partir do aspecto interno representado pelos atos e relações em que se envolvem seus protagonistas, senão pelo ângulo externo a partir do qual seja possivel sentir a sua utilidade" 21

O espírito desse tema é expressado pelos dizeres de Chiovenda, citado, também, por Dinamarco, segundo o qual "il processo deve dare per quanto possible praticamente a chi há um diritto tutto quello e proprio quelo ch egli ha diritto di consiguire" ${ }^{22}$ Esse foi o pensamento do jurista italiano que influenciou (e influencia) os processualistas que ora se debruçam sobre essa questão.

O nascedouro dessa problemática talvez possa ser creditado à lição de José Carlos Barbosa Moreira, em estudo que já citamos anteriormente, para quem esse conceito de efetividade do processo está amparado em cinco "escopos": o processo deve i.) dispor de instrumentos de tutela adequados a todos os direitos do ordenamento; ii.) tais instrumentos devem ser praticamente realizáveis pelos supostos titulares de direitos, ainda que sejam de difícil identifịcação; iii.) é necessário que se assegurem condições propícias para a reconstituição dos fatos sob os quais estará norteada a decisão do magistrado, deste modo aproximandoo cada vez mais da verdade; iv.) o resultado deve assegurar à parte vitoriosa o pleno gozo de utilidade específica a que faz jus segundo o ordenamento jurídico; e v.) tais resultados devem ser obtidos com o mínimo dispêndio de tempo e energia. ${ }^{23}$

Tal tema foi aprofundado por Cândido Rangel Dinamarco em consagrado estudo posterior, que discorre de maneira lapidar sobre a efetividade das decisões e a verdadeira e última função do processo. Veja-se:

"O coroamento de toda atividade desenvolvida com vista a certos objetivos bem definidos e até mesmo individualizada em função deles

20. Instrumentalidade do processo, 1999, São Paulo, Malhciros Editores, p. 271.

21. Fundanentos do Processo Civil Moderno, 2000, São Paulo, Malhciros Editorcs, v. I, p. 592.

22. Saggi di Diritto Processuali Civile, 1930, Roma, v. I, p. 110.

23. ob. cit., pp. $27-42$. 
há de ser representado, naturalmente, pela plena realização dos objetivos eleitos. Falar em efetividade do processo e ficar somente nas considerações sobre o acesso a ele, sobre o seu modo-de-ser e a justiça das decisões que produz significaria perder a dimensão teleológica e instrumental de todo o discurso. Propugna-se pela admissão do maior número possivel de pessoas e conflitos ao processo (universalidade da jurisdição), indicam-se os caminhos para a melhor feitura do processo e advertem-se os riscos de injustiça, somente porque de tudo isso se espera que possam advir resultados práticos capazes de alterar substancialmente a situação das pessoas envolvidas. Não é demais realçar uma vez mais a célebre advertência de que o processo precisa ser apto a dar a quem tem um direito, na medida do que for praticamente possivel, tudo aquilo a que tem direito e precisamente aquilo a que tem direito" 24

A inversão do ônus da prova prevista no art. $6^{\circ}$ inciso VIII, do Código de Defesa do Consumidor, harmoniza-se com perfeição às essas novíssimas diretrizes da processualística, na medida em que contempla o acesso dos consumidores à Justiça e, por outro lado, traz um mecanismo prático e eficiente para que a reconstituição dos fatos aproxime o magistrado da verdade, requisito que, como vimos, constitui um dos objetivos do processo efetivo. Para que se possa alcançar o real sentido dessa norma, mister é entender os próprios fundamentos e sustentáculos do Direito do Consumidor, pois, como muito propriamente diz Luiz Antonio Rizzato Nunes, "entender, então, a produção de provas em casos que envolvam as relações de consumo é compreender toda a principiologia da Lei $n$. 8.078..."."

2. Razões de Ser do Direito Consumerista.

Importante capitulo do Direito Econômico ${ }^{26}$ a proteção do consumidor é indubitavelmente um dos temas mais relevantes, controvertidos e atuais da ciência jurídica hodierna. Nasce como forma de o Estado intervir e regular as ditas relações de consumo, e esboça uma conseqüência da evolução do sistema capitalista e da atuação estatal como regulador da atividade econômica.

Como já tinha apontado o ilustre professor Fábio Konder Comparato, em 1975, "a idéia de uma sistemática proteção do consumidor, nas relações de

24. A Instrumentalidade..., pp. 270-303.

25. Comentários ao Código de Defesa do Consumidor - (arts. I"ao 54), 2000, São Paulo, Editora Saraiva, p. 121 .

26. Cf. Fábio Konder Comparato, A proteção do consumidor: importante capitulo do Direito Econômico, Revista de Dircito Mercantil Nos. 15/16, Editora Revista dos Tribunais, p. 89. 
mercado, é sem dúvida estranha à teoria econômica clássica"27 Na verdade, era isso tema novo não só às ciências econômicas, mas também às jurídicas, uma vez que até os anos 60 do século XX o Direito preocupava-se com os atos de consumo individualmente considerados, estando à margem no fenômeno de consumo em massa.

Consumo é, na linguagem das ciências econômicas, o ato final do processo econômico. Ou, de outro modo, a satisfação de uma necessidade. A Economia lidará, precipuamente, com a administração do problema econômico da escassez, que é, na verdade, a administração dos recursos materiais finitos para o atendimento das necessidades infinitas da sociedade. Como processo econômico entende-se, genericamente, a forma pela qual as riquezas são produzidas e circulam no seio da sociedade até que sejam consumidas. O consumo, portanto, é elemento essencial para a atividade econômica. Daí a importância da regulação das relações de consumo: na verdade, é a proteção de toda a razão de ser do sistema capitalista, que está fundado no fenômeno da sociedade de massas e no consumo das riquezas produzidas (pois não há coerência, no sistema racional de produção capitalista, de produção e circulação de bens sem que haja no mínimo.a potencialidade de serem consumidos).

Direito e Economia, na verdade, são fenômenos sociais imbricados um no outro, pois não há como regular as relações de produção, circulação e consumo de bens sem o Direito, assim como não há meio de entender o Direito a par de uma relação social tão visceral que é a administração da produção social do homem.

O jurista português Carlos Ferreira de Almeida bem assevera que "as ordens juridicas dispõem duma coerência interna que tende a conformar-se com os valores sociais dominantes, expressando portanto também o sistema econômico vigente" ${ }^{28}$ Sendo a Economia uma ciência social, temos como corolário que tal afirmação também lhe serve. Assim, não há como deixar de se entender a razão histórica do Direito do Consumidor, que está atrelado ao desenvolvimento do Direito Comercial e do Direito da Concorrência, sob as influências diretas do surgimento da cultura de massas (ou sociedade de massas), que advém do desenvolvimento do capitalismo após o período das Grandes Guerras Mundiais, fato que alterou profundamente os rumos da Humanidade, proporcionando o repensar de todas as concepções das relações sociais.

Esse fenômeno pôde ser claramente observado nas relações entre o Estado e a vida privada, com atuações aparentemente distintas até então. O sistema que vigorava era o sistema de autonomia de mercado tipicamente liberal, que tinha como separação total os planos decisórios político e econômico, ou seja, a vida pública e a privada. É, pois, o princípio da não-intervenção estatal na autonomia privada, esta baseada em princípios liberais básicos (a disposição da

27. ob. cit., p. 89.

28. Os Direitos dos Consumidores, 1982, Coimbra, Livraria Almcdina, p. II. 
propriedade privada e presunção de que os cidadãos eram livres e iguais, e, conseqüientemente, gozavam de autonomia e racionalidades para contratar).

Com o triunfo dos sistemas capitalista (no Ocidente) e socialista (no Oriente) após o término da Segunda Guerra Mundial (1939-1945), e o surgimento da chamada Guerra-Fria (que, no fundo, significava a competição entre dois sistemas de produção material). Os dois sistemas reformulam suas concepções de atuação do Estado frente ao modo de organização social, política e econômica.

No sistema capitalista, que aqui nos interessa, temos a atuação do Estado como elemento de fomento e reconstrução das bases em que estava assentado seu modo de produção. Com a Europa arrasada após o longo período de guerras, os EUA, que surgem então como nova potência, utiliza o modelo keynesiano de reconstrução econômica ${ }^{29}$ para financiar, através do Plano Marshall, a reconstrução da Europa. Desenvolve-se, então, o chamado EstadoIntervencionista, que preservava e almejava corrigir distorções do modo de produção capitalista ao mesmo tempo em que visava, fundamentalmente, propiciar o Bem-Estar Social, atuando diretamente nas relações privadas. Ao arrepio dos liberais, trata-se da regulação da produção econômica que antes estava nas mãos dos agentes operadores do mercado, passando o processo decisório em âmbito econômico para as mãos do Poder Público ${ }^{30} \mathrm{O}$ Direito Econômico surge, então, como a via pela qual o Estado intervém no sistema econômico, corrigindo as distorções peculiares do capitalismo.

Sobre isso, oportuno lembrar as palavras do ilustre professor José Afonso da Silva, para quem "A atuação do Estado, assim, não é nada mais nada menos do que uma tentativa de pôr ordem na vida econômica e social, de arrumar a desordem que provinha do liberalismo. Isso tem efeitos especiais, porque importa em impor condicionamentos à atividade econômica, do que derivam os direitos econômicos que consubstanciam o conteúdo da constituição econômica..." e, continuando, "Esse embate entre o liberalismo (...) com seu conceito de democracia política, e o intervencionismo ou o socialismo repercute nos textos das constituições contemporâneas, com seus principios de direitos econômicos e sociais, comportando um conjunto de disposições concernentes tanto aos direitos dos trabalhadores como à estrutura da economia e ao estatuto dos cidadãos. "3ı

29. Trata-se das lições de John M. Keynes que, inspirado nos modelos de plancjamento da cconomia pelo Estado, praticado por Lênin na URSS, acabou por formar importante doutrina que scrviu de base para a reconstrução cconômica estado-unidense após a depressão de 1929 , falidos os pressupostos libcrais da incxistência da interferência cconômica

30. Desde o século XIX, o sistema capitalista começava a dispor de instrumentos para a correção de suas falhas de mercado. Nesse contexto cstào: a "Comissào de Comércio entre os Estados" (Interstale Commerce Comission), instituida pelo Interstate Act de 1887, que regulava, principalmente, o transportc ferroviário, c a "Consumers League", hojc "Consumers Union", instituida cm 1891 para a regulação da qualidade produtos c claboraçào de relatórios.

31. Curso de Dircito Constitucional Positivo, 1997, 13* edição, São Paulo, Editora Malhciros, pp. 7 I8-7।9 
Paralelamente a isso deu-se um contínuo e sólido desenvolvimento do setor empresarial, formando-se os grandes conglomerados econômicos (tendo no Japão e nos Estados Unidos seus maiores exemplos), com uma opulenta estrutura de produção de bens e serviços para o mercado de consumo, figura que surge com a abrupta intensificação da produção em série de inúmeros bens para o consumo de uma massa, processo que se inicia na Revolução Industrial, mas que se radicaliza após a segunda metade do século XX, principalmente em decorrência da sofisticação do sistema de crédito e financiamento para o consumo, consolidando esse processo após 1989 , com a derrocada do sistema socialista. A produção de bens e as inovações tecnológicas trouxeram, de fato, um inimaginável progresso material para a humanidade. Entretanto, outro reverso da medalha talvez seja a despersonificação (ou desumanização) dos cidadãos, passando a figurar como um número, tornando seus interesses parte de uma estatística que informa ao sistema a quantidade de bens produzidos e seus destinatários específicos, para que sejam, dessa forma, alocados os fatores de produção. O empresário, antes apenas um fabricante ou um comerciante, é tratado como um fornecedor de produtos e serviços ao mercado de consumo, para serem consumidos pelos integrantes dessa massa.

Jean Calais-Auloy e Frank Steinmetz com muita propriedade retratam esse fenômeno:

“C'est à partir des annés 1960 que les consommateurs posèrent, leur tour, un problème de societé. Cette époque correspond purtant à un developpement économique sans precédent, qui multiplie les bes et les services proposés aux consommateurs. Mais elle correspond aussi à l'acrroissement de la taille des entrerprises, à la complexité plus grande des produits et des services, au développement du crédit, de la publicité et du marketing. Par là s'accroit le desequilibre entre les partenaires économiques: les professionnels se trouven de plus em plus em position de force vis-a-vis des consommateurs" 32

Para a manutenção desse sistema (dito capitalismo de consumo), é necessário que essa massa consuma, de fato, esses bens. Como conseqüência dessa "imposição", surge, nesse século, a ciência do Marketing, desenvolvendo-se, juntamente com o aperfeiçoamento e popularização dos meios de comunicação, as sofisticadíssimas técnicas de propaganda, com seus recursos de indução ao consumo (como a propaganda subliminar e enganosa). O consumo dessa produção tirada dessa nova dinâmica de mercado é, portanto, condição essencial para o vigor desse sistema. A esse fenômeno, que aqui esboçamos sucintamente, dá-se o nome de sociedade de consumo, fenômeno desconhecido no século XIX e em boa

32. Droit de la consommation, 1996, 4: ed., Paris, Éditions Dalloz, pp. I-2. 
parcela do século XX. Daí a importância, aliás, do ato de consumo, para que seja fechado o ciclo econômico. O consumidor é, portanto, a parte vital do sistema.

Tais fenômenos irão repercutir profundamente no âmbito das ciências jurídicas, consoante já foi sugerido pela lição de Carlos Ferreira de Almeida.

Podemos de plano destacar o surgimento de uma situação estrutural, dentro dos negócios jurídicos, de disparidade de forças entre o fornecedor de bens ao mercado de consumo e o consumidor. Isso pode se traduzir por diversas maneiras: condicionamento de fornecimento de um serviço à aquisição de outro, ausência ou insuficiência de informações fundamentais ao consumidor, inclusão de cláusulas abusivas, oferecimento de produtos eivados em vícios e potencialmente lesivos, e o abuso de poder econômico dos fornecedores frente aos consumidores, rompendo, desse modo, o princípio da igualdade e da liberdade contratual, e a relação horizontal que sempre norteou o princípio clássico da noção de contrato ${ }^{33}$ que tanto regia os contratos do sistema liberal. A esse respeito, importante a lição de Ada Pellegrini Grinover e Antonio Herman de Vasconcellos Benjamin:

\begin{abstract}
"A sociedade de consumo, ao contrário do que se imagina, não trouxe apenas beneficios para os seus atores. Muito ao revés, em certos casos, a posição do consumidor, dentro desse modelo, piorou em vez de melhorar. Se antes fornecedor e consumidor encontravam-se em uma situação de relativo equilibrio de poder de barganha (até porque se conheciam), agora é o fornecedor (...) que, inegavelmente, assume a posição de força na relação de consumo e que, por isso mesmo, 'dita as regras' $E$ o direito não pode ficar alheio a tal fenômeno.

O Mercado, por sua vez, não apresenta, em si mesmo, mecanismos eficientes para superar tal vulnerabilidade do consumidor. Nem mesmo mitigá-la. Logo, imprescindivel a intervenção do Estado (...) formulando as normas jurídicas de consumo..." 34
\end{abstract}

Na vulnerabilidade do consumidor está, portanto, fundada a necessidade da regulação (e intervenção) estatal nas relações de consumo. Da consulta do "verbete vulnerável" do dicionário Aurélio, veremos que este é definido pelo "lado fraco de um assunto ou de uma questão, ou do ponto pelo qual alguém pode ser atacado ou ferido". Essa situação é decorrência, como vimos, da ruptura de equilíbrio entre as partes. Nas palavras de Fábio Konder Comparato,

33. O quc podemos obscrvar com a figura dos contratos-padrão ou contratos de adesão, cujas cláusulas, na vcrdade, são impostas pclo fornccedor.

34. Código Brasileiro de Defesa do Consumidor-comentado pelos autores do anteprojeto, 1995, 4* ed., Rio de Janciro, Forensc Universitária, p. 6. 
"o consumidor é, pois, de modo geral, aquele que se submete ao poder de controle dos titulares de bens de produção, isto é, os empresários" 35

A correção de tais desequilíbrios é o escopo principal do Direito do Consumidor. Para Rodolfo Camargo Mancuso, Direito do Consumidor é " $\mathrm{um}$ sistema efetivo de proteção e defesa do consumidor, tendente a resguardar seus interesses ou direitos através de instrumentos processuais adequados" 36 Ou, para Antônio Herman de Vasconcellos Benjamin, "o direito do consumidor, em um primeiro plano, engloba as normas (...) que, ao criarem direitos especificos protegem diretamente o consumidor. Abarca, ainda, normas que visam a assegurar a implementação eficiente desses mesmos direitos, bem como aqueles que asseguram" 37

Jean Calais-Auloy e Frank Steinmetz, a despeito dos fundamentos do Direito do Consumidor, asseveram que:

"L'existence du droit de la consommation se fonde, à mon avis, sur une triple constatation: a) les consommateurs sont naturellement em position de faiblesse vis-à-vis des professionnels ; b) la loi a pour fonction de protéger le faible contre le fort; c) le droit civil classique est impuissant à assurer la protetion des consommateurs" 38

Nesse sentido, temos a idéia de vulnerabilidade como um dos pontos principais que permeia nosso Código de Defesa do Consumidor ${ }^{39}$ Como dissemos, são muitas as formas de constatação dessa vulnerabilidade do consumidor. Newton de Lucca, por exemplo, analisando o art. $4^{\circ}$ do Código de Defesa do Consumidor, que regula a Política Nacional das Relações de Consumo, elencou três principais formas de vulnerabilidade do Consumidor: i.) a publicidade enganosa ou abusiva, ii.)as cláusulas abusivas e iii.) os preços abusivos ${ }^{40}$

Entendemos, pois, que há outra forma de vulnerabilidade do consumidor, que é a vulnerabilidade em sua condição para ingresso em juízo para reclamar a lesão de seus direitos, de modo a ter acesso à prestação jurisdicional para a resolução de seus conflitos, para ser reparado de maneira justa, rápida e eficiente, e de maneira que o possibilite a gozar de seus direitos. Esse é,

35. ob. cit., p. 90. 273

36. Comentários ao Código de Proteção ao Consumidor, 1991, São Paulo, Editora Saraiva, pp. 272-

37. O Direito do Consumidor, Revista dos Tribunais n.670, Agosto de 1991, p. 51

38. ob. cit., p. 16.

39. Antônio Herman Vasconcellos c Bcnjamin, ob. citt, p. 50

40. Direitos do Consumidor, 2000, São Paulo, Edipro, p. 51 
indubitavelmente, um dos pontos essenciais do Direito do Consumidor. Também é, pois, um ponto de entrelaçamento com as mais novas preocupações da processualística moderna: a prestação da tutela jurisdicional efetiva.

Sob esse prisma, então, da conjugação de preocupações da ciência processual moderna e do Direito do Consumidor, passemos a analisar aquilo que pretendemos demonstrar: a função do instituto da inversão do ônus da prova como instrumento de efetividade na prestação da tutela jurisdicional dos interesses dos consumidores.

\section{A Inversão do Ônus da Prova no Código de Defesa do Consumidor.}

Até aqui, mostramos duas linhas distintas de evolução de dois importantes ramos do direito: o Direito Processual Civil e o Direito do Consumidor. Pretendemos, nessa parte, resgatar os dois itens anteriores para demonstrar que a figura da inversão do ônus da prova prevista no $C D C$ é poderoso instrumento de efetivação da tutela dos interesses dos consumidores. Procuraremos demonstrar que o feixe de preocupações dos processualistas mais modernos no tocante ao processo efetivo converge com as preocupações do Direito do Consumidor.

Em primeiro lugar, podemos observar que o desenvolvimento da fase crítica do processo, período em que se desenvolvem as teorias sobre a instrumentalidade do processo - hoje refinada para o escopo de sua efetividade, coincide com o nascimento e desenvolvimento desse novíssimo ramo das ciências jurídicas: o Direito do Consumidor, que se dá, historicamente, a partir dos anos 60 do século passado. E, não é à-toa, pois podemos verificar que em ambos há a utilização do Poder Estatal como instrumento de promoção de acesso não só aos tribunais, mas, isso sim, à "ordem jurídica justa" Em ambos estão presentes os modos de atuação do Estado de Bem-Estar Social, eminentemente intervencionista na vida privada.

Como vimos, o Código Brasileiro de Defesa do Consumidor contemplou como direito básico do Consumidor, em seu art. $6^{\circ}$, inciso VIII, " $a$ facilitação da defesa de seus direitos, inclusive com a inversão do ônus da prova, a seu favor, no processo civil, quando, a critério do juiz, for verossimil a alegação ou quando for ele hipossuficiente, segundo as regras ordinárias de experiências" Há, ainda, a mesma exceção à regra do onus probandi prevista no art. 38 do Código. Veja-se: "O ônus da prova da veracidade e correção da informação ou comunicação publicitária cabe a quem as patrocina" E, finalmente, o CDC, em seu art. 51, inciso VI, reputa nula a cláusula que estabeleça inversão do ônus da prova em prejuizo do consumidor. Analisemos os três casos, isoladamente.

Quanto ao art. 38, oportuno lembrarmos a lição de Antonio Herman de Vasconcellos e Benjamin, que, ao comentar o Código, vaticina que "o dispositivo refere-se ao princípio da inversão do ônus da prova que informa a matéria publicitária. A inversão aqui prevista, ao contrário daquela fixada no art. $6^{\prime \prime}$ 
VIII, não está na esfera de discricionaridade do juiz. É obrigatória. Refere-se a dois aspectos da publicidade: a veracidade e a correção. $A$ veracidade tem a ver com a prova de adequação ao princípio da veracidade. A correção, diversamente, abrange, a um só tempo, os principios da não-abusividade, da identificação da mensagem publicitária e da transparência da fundamentação publicitária" "I

Nada a acrescentar, em nosso estudo, que versa sobre a inversão do ônus da prova como um instrumento a serviço da efetividade processual, dadas as especificidades desse caso. Aspecto importante que o excerto de Benjamin nos traz é, fundamentalmente, a obrigatoriedade da inversão, dadas as peculiaridades da regulação da mensagem publicitária.

O dispositivo do art. 51, VI, por sua vez, trata da nulidade da convenção de cláusula que prevê a inversão do ônus da prova em prejuízo ao consumidor. Tal dispositivo visa coibir a distribuição da carga probatória ao consumidor quando da celebração do contrato. Nelson Nery Júnior ainda complementa: "São igualmente proibidas as cláusulas de inversão de ônus da prova que projetem a certeza ou refutabilidade da existência ou inexistência de um fato, às custas de declaração de consumidor"42

inciso VIII.

Atemo-nos, pois, às discussões contidas no dispositivo do art. $6^{\circ}$,

Um dos pontos centrais do processo efetivo é o acesso à Justiça, como já vimos anteriormente, e lei consumerista brasileira contemplou tal objetivo, quando prevê, expressamente, a facilitação da defesa dos direitos do consumidor. Entendemos, pois, que essa facilitação deva ser a mais ampla possível, posto que não se restringe apenas à inversão do onus probandi, podendo sempre ser aplicada, pelo magistrado, quando verificada a vulnerabilidade do consumidor a partir de situações concretas afirmadas em juízo. Isso porque, em se tratando de relações de consumo, a interpretação da norma deve ser, sempre, a favor do consumidor, pois o Direito do Consumidor é, por excelência, um direito ativista, tendo um de seus fundamentos escorado na proteção do consumidor, como vimos na lição de Calais-Auloy e Steinmetz.

Sobre esse requisito, importantes considerações são traçadas por Cecília Matos, nas conclusões de tese de dissertação de mestrado apresentada à Faculdade de Direito da Universidade de São Paulo, sob a orientação do Professor Kazuo Watanabe:

"A prova destina-se a formar a convicção do julgador, que pode estabelecer com o objeto do conhecimento uma relação de certeza ou de dúvida.

\section{Comentários ao Código, p. 235}

42. Código Brasileiro de Defesa do Consumidor-comentado pelos autores do anteprojeto, 1995, 4" cd., Rio de Janciro, Forense Universitária, p. 353. 
Diante das dificuldades próprias da reconstrução histórica, contenta-se o magistrado em alcançar não a verdade absoluta, mas a probabilidade máxima. A dúvida conduziria o julgador ao estado de "non liquet" caso não fosse elaborada uma teoria de distribuição do ônus da prova. (...)

Neste enfoque, a Lei $n$. 8.078/91 prevê a facilitação da defesa do consumidor através da inversão do ônus da prova, adequando-se o processo à universalidade de jurisdição, na medida em que o modelo tradicional mostrou-se inadequado às sociedades de massa, obstando o acesso à ordem juridica efetiva e justa"43

Atemo-nos, pois a três escopos do processo efetivo elencados por José Carlos Barbosa Moreira, que já elencamos na primeira parte desse opúsculo: o processo deve i.) dispor de instrumentos de tutela adequados a todos os direitos do ordenamento; ii.) é necessário que se assegurem condições propícias para a reconstituição dos fatos sob os quais estará norteada a decisão do magistrado, deste modo aproximando-o cada vez mais da verdade; iii.) o resultado deve assegurar à parte vitoriosa o pleno gozo de utilidade específica a que faz jus segundo o ordenamento jurídico.

A inversão do ônus da prova pode, então, ser vista como um desses instrumentos eficientes para a tutela dos interesses dos consumidores a que alude, na medida em que pode assegurar as tais "condições propícias para a reconstituição dos fatos sob os quais estará norteada a decisão do magistrado, deste modo aproximando-o cada vez mais da verdade", assegurando-lhes que o resultado efetive seu "pleno gozo de utilidade especifica a que faz jus segundo o ordenamento jurídico"

E porque podemos afirmar isso?

Em primeiro lugar, dois são os requisitos para que o juiz possa, "de acordo com as regras ordinárias da experiência", determinar a inversão do onus probandi: a verossimilhança das alegações trazidas em juizo e a hipossuficiência do consumidor.

A verossimilhança da alegação é dirigida, precipuamente, ao discricionarismo do juiz para a determinação da distribuição do onus probandi a cargo do fornecedor. Importante ressaltar que, na hipótese dessa norma, a inversão não é automática, pois está, consoante o próprio texto legal diz, fundada nos critérios do juiz, que é, aliás o destinatário da prova.

O magistrado, ao tomar a decisão, deve estar restrito ao conjunto probatório, e em cima deste deve escorar seu convencimento. Daí que a prova é a ele destinada. Pois, como pondera Pontes de Miranda, "a finalidade processual da prova é convencer o juiz. Além das qualidades humanas, que tem ele, ou de

43. O ônus da prova no Código de Defesa do Consumidor, 1996, São Paulo, p. 236. 
inteligência, de reflexão de raciocinio, o Estado, que fez seu órgão, lhe impõe certas regras de conviç̧ão a que ele tem de obedecer, regras que vão de máximo (sistema da livre conviç̧ão do juiz) até minimo de liberdade (sistema de taxação de prova)" 44

Relativamente ao conceito de hipossuficiência, defendemos a posição de que vulnerabilidade e hipossuficiência são conceitos que não se confundem, embora estejam aproximados pela constatação de desvantagem do consumidor em relação ao fornecedor. Podemos dizer, grosseiramente, que hipossuficiência é a faceta processual da vulnerabilidade do consumidor, assentada, principalmente, na dificuldade do ingresso do consumidor em juízo para a defesa de seus direitos. Vemos, aqui, que uma das preocupações do Código de Defesa do Consumidor é a de propiciar a efetividade processual na satisfação da tutela jurisdicional na facilitação dos cidadãos da provocação do Estado para a pacificação de litígios específicos.

José Rogério Cruz e Tucci, em parecer, traz importante contribuição para a conceituação da situação de hipossuficiência: "Note-se que a clássica regra dà distribuição do ônus da prova, no âmbito das relações de consumo, poderia tornar-se injusta pelas dificuldades da prova de culpa do fornecedor, em razão da disparidade de armas com que conta o consumidor para enfrentar a parte melhor informada. É evidente que o consumidor, em muitas hipóteses, não tem acesso às informações sobre as quais recairia todo o seu esforço para a prova dos fatos alegados. Ora, a informação, na conjuntura social, moderna, é sinônimo de poder. Dai que, por simples questão de lógica é que o autor fica, em principio, dispensado de provar, carreando-se tal ônus ao produtor, que é quem possui o monopólio do monopólio dos dados atinentes ao processo de fabricação " 45

Importante precedente nacional foi registrado no julgamento de um recurso especial no Superior Tribunal de Justiça do Brasil, com ampla repercussão em todo o mundo. Trata-se de ação civil coletiva por danos individuais homogêneos proposta pela Associação de Defesa da Saúde do Fumante - ADESF em face de Philip Morris Marketing S/A. Versa sobre a inversão do ônus da prova, considerando a hipótese de que a indústria de cigarros está muito mais apta a comprovar que a nicotina não causa dependência que a associação autora provar que ela causa ${ }^{46}$

Cruz e Tucci defende que a hipossuficiência não diz respeito à natureza econômica, mas fundamentalmente com o monopólio, pelo fornecedor, da informação. Ousamos, pois, discordar, uma vez que poderá haver situações nas quais é a vulnerabilidade econômica do consumidor o impedimento para o ingresso em juizo, principalmente no tocante aos encargos da produção da prova pericial.

44. Comentários ao Código de Processo Civil, 1999, 3 cd., Rio de Janciro, Tomo IV, p. 260.

45. Código do Consumidor e Processo Civil - Aspectos polêmicos. Revista dos Tribunais n.67I, sctembro de 1991, p.33

46. REsp n. 140.097/SP; STJ; Rclator Min. Ccsar Asfor Rocha; julgado 04.05.2000; un. 
Trabalhemos no vasto campo das hipóteses, com um singelo exemplo: consumidor bate seu automóvel novo, soltando-se o banco, por ocasião do impacto, sendo seu corpo comprimido contra o pára-brisa, lesionando-lhe a coluna. Ingressa em juizo requerendo indenização fundada na responsabilidade do fabricante pelo fato do produto. Na fase de instrução probatória, seria necessária a destruição de um automóvel igual contra um muro, para que se prove que a velocidade era compativel com as alegações do consumidor, de que houve defeito na fabricação do veículo, e não imprudência sua. Pergunta-se: terá o autor que arcar com o novo automóvel, bem que possui alto valor agregado? Entendemos que, se o juiz possa entender que há tal prova e pode influenciar sua conviç̧ão, poderá decidir pela inversão do ônus da prova, em desfavor do fabricante.

Eis, pois, outro ponto fundamental desse instituto: o momento de inversão do onus probandi. Cecília Matos, após tecer um panorama abrangente das teorias sobre a prova e sobre o ônus da prova, defende nas conclusões de seu trabalho que "a inversão do ônus da prova é direito de facilitação da defesa e não pode ser determinada senão após o oferecimento e valoração da prova, se e quando o julgador estiver em dívida" ${ }^{47}$

Divergimos nesse ponto. Entendemos que o juiz pode determinar a qualquer tempo a inversão do ônus da prova, constados os requisitos exigidos no texto legal (verossimilhança de alegações e hipossuficiência). Mais que isso, somos propensos a defender que, no bom andamento processual, o momento mais oportuno, em tese, é o momento de saneamento do processo, onde se estabeleçam as regras sobre as quais serão lançadas as bases probatórias.

Vê-se, portanto, que a inversão é de cunho flagrantemente facilitador do acesso à Justiça. Está escorada na contribuição para a rápida, eficaz e efetiva satisfação da tutela jurisdicional dos conflitos dos consumidores. Não há como dissociar os escopos do processo efetivo de tal instituto, uma vez que este é um meio eficaz de realização da efetividade da tutela jurisdicional, sendo a inversão a expressão, no texto legal, dessa nova postura crítica da processualística moderna. Entendemos, também que tal instituto poderia ser muito alargado em outros campos do Direito, notadamente nos litígios que envolvem questões ambientais, em que há, muitas vezes, a submissão da população ao poder econômico dos agentes poluidores.

São Paulo, dezembro de 2001. 